\title{
ANTIMICROBIAL EFFECTS OF THE ETHANOLIC EXTRACTS AND ESSENTIAL OILS OF TANACETUM VULGARE L FROM ROMANIA
}

\author{
Maria Lucia MUREŞAN ${ }^{1}$ \\ Faculty of Farmacy, Lucian Blaga University of Sibiu, Romania
}

\begin{abstract}
This paper investigates the antimicrobial action of the extracts and essential oil of wildgrowing Tanacetum vulgare L on: Staphylococcus aureus, Escherichia coli, Pseudomonas aeruginosa and Bacilus subtilis, using the diffusion disc method. The essential oils but also the ethanolic extracts tested exhibited moderate action on Staphilococcus aureus and Bacillus subtilis and low action on E. coli and Pseudomonas aeruginosa. The moderate antimicrobial activity is related to the amount of some chemical components of the essential oil of $T$. vulgare flos. Thus, this paper presents also the quantitative and qualitative analysis of the essential oils of T. vulgare harvested from two different habitats. The essential oils obtained by steamdistillation were analysed by gas-cromatography coupled with mass spectrometry (GC-MS).
\end{abstract}

Keywords: essential oil, extract, Tanacetum vulgare, antimicrobial effects

\section{INTRODUCTION}

From ancient times, the beneficial effects of plant extracts in healing or treating diseases were known (Tabata et al., 1988). The properties of these plants are based on their composition, rich in bioactive compounds, such as essential oil, polyphenols, flavonoids or tannins. The essential oils extracted from plants contain terpenes and its subclasses: monoterpenes and sesquiterpenes, which have antibacterial, anti-septic, anti-inflammatory properties (Wallace,2004; Bagci,2010; Georgescu and Mironescu, 2011; Benedec et al.,2013; Mureşan et al.,2014; Şandru 2015). The mechanism of the action of the terpenes is not fully known. There is only an assumption that the cell membrane is distroyed by the lipophilic compounds.

Scientific research has reported positive results on the antimicrobial activity of the essential oils of Tanacetum vulgare harvested outside Romania (Cowan

\footnotetext{
${ }^{1}$ Corresponding author. Mailing adress: Mureşan Maria Lucia, Faculty of Pharmacy, Lucian Blaga University of Sibiu, Romania, , Lucian Blaga street no 2A.E-Mail: nartea_maria@yahoo.de
} 
1999; Jussi-Pekka et al. 1999; Salamcia et al., 2007; Nurhayat et al., 2007; Kaan et al. 2010). Therefore, this paper aims are, to analyse the antimicrobial effect on Staphylococcus aureus, Escherichia coli, Pseudomonas aeruginosa and Bacillus subtilis of the essential oils, but also of the ethanolic extracts of T. vulgare harvested in Transylvania/ Romania. In order to explain the antimicrobial effect, another aim of this research is to evaluate the chemical composition of the essential oil.

\section{MATERIALS AND METHODS}

Plant material: headflowers of T. vulgare harvested from two different habitats of Transylvania, Alba and Sibiu.

Two essential oils , U1- essential oil of T. vulgare harvested from Sibiu, U2essential oil of T. vulgare harvested from Alba (Tanacetum aetheroleum) and two ethanolic extracts, $\mathrm{T} 1$ and $\mathrm{T} 2$, obtained from the same material were used. For comparison the essential oils were obtained by steam distillation of the dried material in accordance with the Romanian Pharmacopoeia. The distillated oils were dried over anhydrous sodium sulfate and stored in tightly closed dark vials at $4^{\circ} \mathrm{C}$ until the analyses were carried out.

Essential oil analysis procedure: The three samples were diluted with cyclohexane in a $1: 1$ proportion and a volume of $0.1 \mu \mathrm{L}$ was injected. An Agilent 6890 Series gas-chromatograph coupled with a Hewlett Packard 5973 mass spectrometer, and a capillary Permabond column SE-52, $(60 \mathrm{~m} \times 450$ FARMACIA, 2013, Vol. $61,30.25 \mathrm{~mm}, 0.25 \mu \mathrm{m}$ ) were used. The injector and detector temperatures were kept at $250^{\circ} \mathrm{C}$ and $280^{\circ} \mathrm{C}$, respectively. Helium was used as a carrier gas, with a flow rate of $0.6 \mathrm{~mL} / \mathrm{min}$; oven temperature programmed was $60-240^{\circ} \mathrm{C}$ at a rate of $3^{\circ} \mathrm{C} / \mathrm{min}$. Mass spectrometry (MS) analysis was performed in the same conditions, with an ionization voltage of $70 \mathrm{eV}$ and mass range was from 35-700 u.i.m. Identification of individual compounds was performed by comparison of their mass spectra with those of the internal reference mass spectra libraries (Wiley 275 and NIST 98) (Mureşan, 2014; Oprean et al.1998).

To determinate the antimicrobial activity we used the disk diffusion method on culture Mueller-Hinton medium, agar poured uniformly on a thin layer of 4mm, pH 7.2 (Marian 2013; Şandru, 2015; Mironescu et al., 2010). As test microorganisms it was used Staphylococcus aureus ATCC 25923, Escherichia coli ATCC 25922, Pseudomonas aeruginosa ATCC 27853 and Bacillus subtilis. The inoculated plates were then incubated at $37^{\circ} \mathrm{C}, 10$ minutes. Filter paper discs $(6 \mathrm{~mm}$ in diameter) were impregnated with $15 \mu \mathrm{L}$ essential oil and $15 \mu \mathrm{L}$ ethanolic extract and placed on seeded plates. For comparison there were used 2 antibiotics, Gentamicine and Ciprofloxacine. In the concentration of 10 
$\mathrm{mg} / \mathrm{disc}$ The activity was determined after maintaining the samples for 24 hours at $37^{\circ} \mathrm{C}$ (Benedec et al., 2013; Marian et al., 2013; Moldovan et al., 2014)

\section{RESULTS AND DISCUSSIONS}

The essential oils' level ( $\mathrm{mL}$ essential oil $/ 100 \mathrm{~g}$ natural product $\pm \mathrm{SD}$ ) for the two samples was determined by steam distillation: $0.64 \% \pm 0.03$ (sample 1 , headflowers harvested from Sibiu in august 2013) and $0.55 \% \pm 0.03$ (sample 2, headflowers harvested from Alba in august 2013). Considering the quantity of essential oils, August was the optimal period for harvesting the natural product. In the literature, the reported levels of essential oil in Tanacetum vulgare headflowers are between $0.4 \%$ and $1.1 \%$ (Mureşan ML, 2014, Tetenyi et al. 1975).

The main compounds of the essential oils of $T$. vulgare flos and their levels are presented in Table 1 (percentage value represents the mean of three determinations $\pm \mathrm{SD}$ ). The isolated oils were analysed by GC-MS and there were identified between 32(in the oil of headflowers of $T$. vulgare collected from Alba) and 42 compounds (in the oil of the headflowers collected from Sibiu). The constituents given in Table 1 made up 54.01\% - $84.98 \%$ of each oil content.

In the essential oils obtained from sample 1, 14 compounds were identified, representing $87.24 \%$, whilst in sample 2, 16 compounds, representing $89.07 \%$ of the essential oil. The basic components were represented by monoterpenes and sesquiterpenes. Regarding the antimicrobial activity, the main components responsible for this activity, also reported in other scientific research, are camphor, borneol, thymol. The results showed a higher concentration of this components in the sample harvested from Alba. The antimicrobial effect of these samples was tested. The diameter of the inhibition zones in the Petri dishes are presented in Table 2 .

Table 1. Chemical composition of the essential oils of wild T. vulgare from Sibiu (sample 1) and Alba (sample 2).

\begin{tabular}{|l|c|c|c|c|}
\hline \multicolumn{1}{|c|}{ Compound } & $\mathbf{t}_{\mathbf{R}}$ & $\mathbf{I}$ & Sample 1, \% & Sample 2, \% \\
\hline 1,8-Cineol (MT) & 8.18 & 1030 & 3.50 & 3.27 \\
\hline Artemisia ketone (MT) & 9.20 & 1060 & 2.19 & 7.88 \\
\hline Artemesia alcohol (MT) & 10.00 & 1083 & - & 0.70 \\
\hline alpha-Thujone (MT) & 10.92 & 1108 & 24.81 & 13.21 \\
\hline beta-Thujone (MT) & 11.25 & 1116 & 14.41 & 12.79 \\
\hline Camphor (MT) & 12.35 & 1144 & 1.16 & 10.17 \\
\hline Borneol L (MT) & 13.26 & 1162 & 0.93 & 9.34 \\
\hline 4-Terpineol (MT) & 13.69 & 1177 & - & 0.75 \\
\hline Myrtenol (MT) & 14.45 & 1197 & - & 2.99 \\
\hline
\end{tabular}




\begin{tabular}{|l|c|c|c|c|}
\hline Crysanthenyl acetat (ST) & 16.25 & 1239 & 25.84 & 20.06 \\
\hline Piperitone (MT) & 16.89 & 1254 & - & 0.88 \\
\hline Carveol (MT) & 18.31 & 1288 & - & 2.89 \\
\hline Thymol (MT) & 18.50 & 1293 & 0.60 & 1.55 \\
\hline Azulene (MT) & 18.79 & 1300 & 0.57 & 1.16 \\
\hline p-Cymene (MT) & 19.88 & 1326 & 0.56 & - \\
\hline Spathulenol (ST) & 29.93 & 1575 & 0.76 & - \\
\hline (-)-Caryophyllene oxide (ST) & 30.14 & 1580 & 3.07 & - \\
\hline Cubenol (ST) & 31.91 & 1627 & 3.31 & 0.49 \\
\hline (+,-)-.beta.-Himachalene (ST) & 32.95 & 1655 & 5.53 & 0.94 \\
\hline Total & & & $\mathbf{8 7 . 2 4}$ & $\mathbf{8 9 . 0 7}$ \\
\hline
\end{tabular}

MT- Monoterpene, ST- Sesquiterpene

Table 2. Antimicrobial activity of the essential oils and ethanolic extracts of T. vulgare harvested from Tranylvania (Alba and Sibiu) measured in mm after 24h.

\begin{tabular}{|c|c|c|c|c|}
\hline \multirow{2}{*}{$\begin{array}{l}\text { Extract/control } \\
\text { product }\end{array}$} & \multicolumn{4}{|c|}{ Diameter of the inhibition zones } \\
\hline & $\begin{array}{c}\text { S. aureus } \\
\text { ATCC } \\
25923\end{array}$ & B. subtilis & $\begin{array}{l}\text { E.coli } \\
\text { ATCC } \\
25922\end{array}$ & $\begin{array}{c}\text { Ps. aeruginosa } \\
\text { ATCC } 27853\end{array}$ \\
\hline U1 & 12 & 11 & 7 & 7 \\
\hline $\mathrm{U} 2$ & 16 & 12 & 8 & 6 \\
\hline $\mathrm{T} 1$ & 11 & 10 & 6 & 6 \\
\hline $\mathrm{T} 2$ & 12 & 11 & 7 & 5 \\
\hline Gentamicine & 28 & 23 & 23 & 21 \\
\hline Ciprofloxacine & 30 & 23 & 36 & 20 \\
\hline
\end{tabular}

Both, essential oils and ethanolic extracts (70\%), have moderate activity on Staphylococcus aureus (U1/U2 $=16 \mathrm{~mm} / 12 \mathrm{~mm}, \mathrm{~T} 1 / \mathrm{T} 2=12 \mathrm{~mm} / 11 \mathrm{~mm})$ and Bacillus subtilis (U1/U2 $=12 \mathrm{~mm} / 11 \mathrm{~mm}, \mathrm{~T} 1 / \mathrm{T} 2=11 / 10)$ and low activity on $E$. coli $(\mathrm{U} 1 / \mathrm{U} 2=8 \mathrm{~mm} / 7 \mathrm{~mm}, \mathrm{~T} 1 / \mathrm{T} 2=7 \mathrm{~mm} / 6 \mathrm{~mm})$ and Pseudomonas aeruginosa $(\mathrm{U} 1 / \mathrm{U} 2=6 \mathrm{~mm} / 7 \mathrm{~mm}, \mathrm{~T} 1 / \mathrm{T} 2=5 \mathrm{~mm} / 6 \mathrm{~mm})$. In comparison to the plant material, the two antibiotics, Gentamicin and Ciprofloxacin have proved to have significantly higher antimicrobial activity.

These results are in accordance with other similar researches on volatile oils extracted from $T$. vulgare harvested from outside of Romania.

The modest results are explained by the presence in certain concentration of terpenes, camphor, borneol and 1,8-cineol, in both samples. The best antimicrobial result was determined by the sample harvested from Alba, activity reflected also by the higher concentration of the chemical constituents. 


\section{CONCLUSIONS}

From the obtained results it can be concluded that the selected essential oils, but also the ethanolic extracts feature antimicrobial activity. All 4 samples exhibited moderate activity on Staphylococcus aureus and B. subtilis and low activity on E. coli and Pseudomonas aeruginosa. The antimicrobial activity of T. vulgare harvested from two different habitats, Sibiu and Alba, can be explained by the moderate presence of the three terpenes, camphor, 1,8-cineol and borneol. Thus, the sample harvested from Alba showed better results concerning the chemical composition and also the antimicrobial activity. The majority of the chemical components of both samples was represented by monoterpenes $(48,73 \%$ for sample 1 and $67,58 \%$ for sample 2$)$, and sesquiterpenes $(38,51 \%$ for sample 1 and $21,49 \%$ for sample 2$)$.

\section{REFERENCES}

1. Bagci, E., Kocak, A.(2010). Essential oil composition of two endemic Tanacetum (T. Nitens (Boiss.\& Noe) Grierson and T. Argentum (Lam.) Willd. Subsp.argentum) (Asteraceae) taxa, growing wild in Turkey, Industrial Crops and Products 31, 542- 545.

2. Benedec, D., Vlase, L., Oniga, I., Mot, A.C., Damian, G, Hanganu, D, Duma, M, Silaghi-Dumitrescu, R. (2013). Polyphenolic composition, antioxidant and anitbacterial activities for two Romanian subspecies of Achillea distans Waldst. Et Kit. Ex Willd. Molecules. 18(8), 8725-39.

3. Cowan Murphy, M.(1999), Plants Products as Antimicrobial Agents, Clinical Microbiology Reviews, 12 (4), 569- 582.

4. Jussi-Pekka, R., Remes, S.,Heinonen, M.,Hopia, A, Kaekoenen,M., Kujala T., Pihlaja, K., Vuorela, H., Vuorela, P. (2000). Antimicrobial effects of Finnish plant extracts containing flavonoids and other phenolic compounds. International Journal of Food Microbiology 56 , 3-12.

5. Kaan, P., Fatih, D., Betul, D., Neyhun, G., Kemal Husnu Can, B. (2010). Essential oil composition and antibacterial activity of Tanacetum argentum (Lab.) Schulty Bip. Ssp. Amani Heywood from Turkey, Journal of Oleo Science, 59, (7) 361- 367.

6. Marian, E., Mureşan, M., Jurca, .T, Vicaş, L (2013). Evaluation of antimicrobial activity of some types of inclusion complexes of Erythromycin with $\beta$-cyclodextrin on Staphylococcus aureus. Farmacia 3(61):518.

7. Mironescu M., Georgescu C., Mironescu I. D., In vitro testing of fungicidal activity of four new biocides on moulds biodeteriorating the monumental surfaces, Annals of the Romanian Society for Cell Biology, 2010, 15 (2): $156-161$ 
8. Moldovan, R.I., Oprean, R., Benedec, D., Hanganu, D., Duma, M., Oniga, I., Vlase, L.(2014). LC-MS analysis, antioxidant and antimicrobial activities for five species of Mentha cultivated in Romania.Dig J. Nanomater Bios. 9:559-66.

9. Mureşan, M.L., Georgescu, C., Păltinean, R., Gligor, F., Crăciuna, M.T., Oprean, R.(2014). Botanical and phytochemical studies on Tanacetum vulgare L. from Transylvania. Acta Medica Transilvanica. 2(4): 145- 147.

10. Nurhayat, T., Fatih, D., Betul, D.(2007). Composition, enantiomeric distribution, and antimicrobial activity of Tanacetum argentum subsp. flabellifolium essential oil, Journal of Pharmaceutical and Biomedical analysis $45,714-719,715$.

11. Oprean, R, Tămaş, M., Săndulescu, R., Roman, L.(1998). Essential oil analysis. I. Evaluatio.n of essential oils composition using both GC and MS fingerprints. Journal of Pharmaceuticaland Biomedical Analysis 18:651657.

12. Salamcia, E., Saban, K., Recep, K., Ahmet, C., Yusuf, K. (2007).Chemical compositions, antimicrobial and herbicidal effects of essential oils isolated from Turkish Tanacetum aucheranum and Tanacetum chiliophyllum var. Chiliophyllum, Biochemical Systematics and Ecology, Volume 35, 569581.

13. Şandru, D.M. (2015). Antimicrobial effect of Escherichia coli on essential oils derived from romanian aromatic plants. Acta Universitatis Cibiniensis Series E: Food Technology, XIX (1).

14. Tabata, M., Honda, G., Sezik, E. (1988). A report on traditional medicine and medicinal plants in Turkey. Faculty of harmaceutical sciences, Kyoto University.

15. Tetenyi, P., Kapos, P., Hethelyi, E.(1975) Variations in the essential oils of Tanacetum vulgare. Phytochemistry, 14(7): 1539-1544.

16. Wallace, R.J.,(2004). Antimicrobial properties of plant secondary metabiltes. Proc. Nutr. Soc. 63, 621-629 